\title{
Effect of Gender on Feedback Associated with a Direct Clinical Observation Tool Used during Clerkship at McMaster University
}

$\mathrm{J}$ Gen Intern Med

DOI: $10.1007 / \mathrm{s} 11606-020-06399-5$

(c) Society of General Internal Medicine 2021

\section{INTRODUCTION}

Direct observation assessments, including work-based assessments, are increasingly common across undergraduate medical clerkships. However, the validity of work-based assessments is threatened by assessor biases. Specifically, significant interactions between assessor and student gender have been noted. ${ }^{1,2}$ The type of feedback given to residents may also vary by gender with males given more positive feedback on stereotypically masculine traits. ${ }^{3}$

The McMaster direct observation tool (MacDOT) is an online educational tool developed for the undergraduate medical education (UGME) program at McMaster University. Students are observed having direct interactions with patients, and they get immediate feedback on the encounter. These include clinical and professional competency domains. The student chooses the competency for assessment and the observer to provide feedback. ${ }^{4}$ Residents and faculty are able to act as observers. The students complete 10 MacDOTs in a 6week rotation.

This study explores if medical students strategically seek out feedback on key clinical competencies from observers based on gender.

\section{METHODS}

A retrospective analysis of all MacDOTs completed in 2018 by clinical clerks during their internal medicine core rotation was performed. Gender was assigned to students and observers as indicated on the public College of Physicians and Surgeons of Ontario website. Differences between gender of observer and student and by type of competency (clinical competencies - taking a history, performing a physical exam, completing a procedure versus professional competencies - communicating with patients, critical appraisal of the literature to guide clinical care) were compared using

Received July 13, 2020

Accepted December 3, 2020 a chi-squared statistic. The Hamilton Integrated Research Ethics Board approved this study (Project Number 7934-C).

\section{RESULTS}

There were 2071 evaluations or DOT interactions included in this study. For 11 of those evaluations, faculty gender was not indicated. Those 11 evaluations were removed from the overall count. Table 1 shows the distribution of faculty gender across competencies and students. Table 1 shows the distribution of faculty gender across competencies and students is fairly equivalent. The total chi-squared statistic is not significant $\left(X^{2}=2.3, p=0.13\right)$. The chi-squared statistic for clinical observations $\left(X^{2}=0.6\right)$ and for procedural observations $\left(X^{2}=\right.$ 2.5 ) was also not significant ( $p=0.4$ and 0.1 respectively). (IBM SPSS Statistics, Copyright IBM Corporation and its licensors 1989, 2019. Version 26. Trademark of international business machines corp).

\section{DISCUSSION}

In this study, there was an equal distribution of male and female observers for male and female students. There was no effect of gender when choosing an observer for clinical or professional competencies. There may be several reasons for the findings reported in this study. There are more male observers available in the Internal Medicine program at McMaster University which may skew the data. The formative, low stakes nature of the MacDOT assessments may have confounded the lack of influence of gender reported in other studies. ${ }^{1-3}$ Conflicting data has been found in Internal Medicine residency programs regarding the influence of gender on learner assessments. ${ }^{5,} 6$ Perhaps factors unique to the McMaster context are playing a role, such as equity and unconscious bias training of students and faculty.

A limitation of this study is that we have characterized gender as a binary phenomenon that does not reflect a contemporary view of gender as non-binary. In addition, this single-centre study may have particular contextual confounders that prevent generalization of these sociocultural findings more broadly.

Future research should evaluate the nature and quality of narrative comments included in MacDOT assessments. 
Table 1 Counts of Faculty who Evaluated Students, Broken Down by Gender. Percentages Indicate the Percent of Faculty who Submitted Evaluations within Each Context

\begin{tabular}{llll}
\hline \hline Faculty fender & & & \\
\hline Competency & Student gender & Female & Male \\
\hline Clinical & Female & $318(54 \%)$ & $457(56 \%)$ \\
& Male & $273(46 \%)$ & $361(44 \%)$ \\
Professional & Female & $144(52 \%)$ & $219(58 \%)$ \\
& Male & $132(48 \%)$ & $156(42 \%)$ \\
\hline
\end{tabular}

Stereotypical gender-based language in the narrative comments was not assessed in this study. This study demonstrates that gender is not a factor when a medical student selects an observer from a large potential group of observers to provide a formative, low stakes assessment. Future research should explore the language used in formative, low stakes assessments to determine the influence of gender.

Helen Neighbour, MB BS, MRCP (UK), $P h D^{1,2}$

Sandra Monteiro, $\mathrm{Ph} \mathrm{D}^{3,4}$

Mark Lee, BHSc, DipCLS ${ }^{4,5,6}$

Yifei $W u, B S c, M D^{7}$

Anthony Levinson, MD, MA, MSC, FRCPC ${ }^{8,9}$

Jonathan Sherbino, MD, MEd, FRCPC, FAcadMEd ${ }^{1,4,6}$

${ }^{1}$ Department of Medicine, McMaster University,

Hamilton, ON, Canada

${ }^{2}$ Firestone Institute for Respiratory Health, St Joseph's Healthcare Hamilton,

Hamilton, Canada

${ }^{3}$ Health Research Methods, Evidence and Impact, McMaster University,

Hamilton, Canada

${ }^{4}$ McMaster Education Research, Innovation and Theory, David Braley Health Sciences Centre,

Hamilton, Ontario, Canada

${ }^{5}$ Bachelor of Health Sciences (Honours) Program, McMaster University,

Hamilton, ON, Canada

${ }^{6}$ McMaster Education Research, Innovation, and Theory (MERIT) program, McMaster University, Hamilton, ON, Canada
${ }^{7}$ Internal Medicine, University of British Columbia, Vancouver, BC, Canada

${ }^{8}$ John R Evans Chair in Health Sciences Educational Research and Instructional Development, McMaster University,

Hamilton, ON, Canada

${ }^{9}$ Division of e-Learning Innovation, Faculty of Health Sciences, MDCL 3117, McMaster University, Hamilton, ON, Canada

Corresponding Author: Helen Neighbour, MB BS, MRCP (UK), PhD; Department of Medicine, McMaster University, Hamilton, ON, Canada (e-mail: neighbh@mcmaster.ca).

Compliance with Ethical Standards:

Conflict of Interest: Dr. Levinson has joint ownership/Copyright in the MacDot application. The other authors have no conflicts to disclose.

\section{REFERENCES}

1. Wang-Cheng RM, Fulkerson PK, Barnas GP, Lawrence SL. Effect of student and preceptor gender on clinical grades in an ambulatory care clerkship. Acad Med. 1995;70(4):324-326. https://doi.org/10.1097/ 00001888-199504000-00018

2. Riese A, Rappaport L, Alverson B, Park S, Rockney RM. Clinical Performance Evaluations of Third-Year Medical Students and Association With Student and Evaluator Gender. Acad Med. 2017;92(6):835-840. https://doi.org/10.1097/ACM.0000000000001565

3. Mueller AS, Jenkins TM, Osborne M, Dayal A, O'Connor DM, Arora VM. Gender Differences in Attending Physicians' Feedback to Residents: A Qualitative Analysis. J Grad Med Educ. 2017;9(5):577-585. https://doi. org/10.4300/JGME-D-17-00126.1

4. Levinson AJ, Rudkowski J, Menezes N, Baird J, Whyte R. Use of Mobile Apps for Logging Patient Encounters and Facilitating and Tracking Direct Observation and Feedback of Medical Student Skills in the Clinical Setting. In: Auer M, Tsiatsos T (eds) Mobile Technologies and Applications for the Internet of Things. IMCL 2018. Advances in Intelligent Systems and Computing, vol 909. Springer, Cham; 2019

5. Rand VE, Hudes ES, Browner WS, Wachter RM, Avins AL. Effect of evaluator and resident gender on the American Board of Internal Medicine evaluation scores. J Gen Intern Med. 1998;13

6. Holmboe ES, Huot SJ, Brienza RS, Hawkins RE. The association of faculty and residents' gender on faculty evaluations of internal medicine residents in 16 residencies. Acad Med. 2009;84(3):381-384.10):670-674.

Publisher's Note: Springer Nature remains neutral with regard to jurisdictional claims in published maps and institutional affiliations. 